\title{
Unemployment, depression, and health: a look at the African-American community
}

\author{
Eunice Rodriguez, Josephine A Allen, Edward A Frongillo Jr, Pinky Chandra
}

\begin{abstract}
Objectives-While the unemployment rate of African-American people is more than twice that of the white population, the research on the impact of unemployment on the health of this population is scarce. This study analysed the impact of unemployment on depression and well being among African-American people, and the factors associated with well being. Methods-Logistic and multiple regression models were used to analyse panel data collected in the National Survey of Families and Households 1987-1992. African-American (1369) and white (6660) respondents were analysed separately. Outcome variables included an index of depression and self reported health status. Main findings-Differences between employment and unemployment groups were less significant for African-Americans than for the white population in predicting depression and well being. Health enhancing factors such as education and wealth were significantly associated with better health and lower depression indices among the white population but not consistently so among AfricanAmericans. Satisfaction with personal relationships was the strongest predictor of well being for both groups.

Conclusion-Research should focus on the special needs and circumstances of African-Americans, because protective factors may not have the same impact in different groups of the population.

(f Epidemiol Community Health 1999;53:335-342)
\end{abstract}

During the past 20 years unemployment levels have increased dramatically in Western countries, and reducing unemployment has dominated the policy agenda of industrialised countries. The USA has been very successful in lowering the overall unemployment rate to 5.3 per cent during the first quarter of 1997, but it remains much higher for some groups of the population. While the seasonally adjusted unemployment rate for the white population is down to 4.5 per cent, it is 10.9 per cent for African-Americans, ${ }^{1}$ and 8.3 per cent for Hispanics of all origins.

Not only are African-Americans among the hardest hit by unemployment, but they tend to occupy lower paying occupations. For instance, while in 1993 the median weekly earnings for full time wage and salaried white workers were $\$ 478$, they were only $\$ 370$ for AfricanAmerican workers. ${ }^{2}$ Inheritances are also an important contributor to wealth differences between African-American and white people. It has been estimated that the contribution of lifetime inheritances to wealth differences is comparable to that resulting from lifetime earning differences. ${ }^{3}$ In addition, among African-American family heads, labour force participation rates are declining and female headed households are rising. AfricanAmericans are over-represented in female householder families and in general tend to stay in poverty longer than white people.

There is an extensive social science and epidemiological literature on the relation between poverty, household income, and health, ${ }^{4-10}$ which reports the health impact of unemployment. Some studies have shown that persons in poorer health are more likely to lose their jobs and persons in better health are more likely to be re-employed, ${ }^{11-13}$ supporting what is called a selection process, which may explain - at least partially-health differences between employed and unemployed persons. However, a large number of qualitative $e^{14-17}$ and quantitative ${ }^{18-21}$ studies have provided a wealth of empirical evidence relative to the health effects of unemployment. An increase in mortality rates, depression, substance abuse, admissions to psychiatric hospitals, and violence are among the most salient outcomes associated with a rise in unemployment levels. ${ }^{22-25}$ In addition, job loss is associated with the loss of health insurance in the USA.

Although the health impact of unemployment has been widely studied, there is a paucity of information on the social interventions that could have a long term protective impact on mental and overall health status. In addition, ethnicity is usually included in unemployment analyses as a controlling variable among other sociodemographic characteristics. Rarely are different groups analysed separately, limiting our understanding of the different dynamics and mechanisms operating in the prediction of mental and general health status. Furthermore, the lack of adequate longitudinal data has made it difficult to study those elements that could have long term protective impacts on both mental health, and family and social functioning, during the transition from joblessness to stable employment.

This paper examines the factors that explain the impact of unemployment on depression and overall health perception among both African-American and white people separately. We use a longitudinal design to clarify the direction of the relations. We include an analysis of how public assistance programmes could enable people to cope successfully during periods of unemployment. We explore in detail sex 
differences elsewhere (E Rodriguez, et al, American Evaluation Association annual meeting, Atlanta, 1996).

It has been argued that the differences between ethnic or racial groups are mostly explained by socioeconomic differences, ${ }^{26}{ }^{27}$ but most studies show that adjusting for socioeconomic status reduces but does not eliminate health disparities among ethnic groups. ${ }^{28-30}$ Race or racism, or both, also plays a part in determining employment status, education, or income. Research to understand the impact of ethnicity and socioeconomic status on health has been increasing in recent years ${ }^{31}{ }^{32}$ but more research is still needed if we are to understand the complex interactions of these factors. ${ }^{33}$ Here, we analyse African-American and white people separately to investigate possible differences between these two groups in the relations that multiple factors have with depression and general health assessment. We are interested in analysing the predictors of depression among each group independently.

\section{Methods}

SAMPLE

We analysed panel data collected in the National Survey of Families and Households (NSFH) 1987-1992, which combines data on unemployment, the receipt of unemployment compensation, perception of health status, and mental health outcomes. The 1987 NSFH study interviewed 13014 respondents, including an over-sample of minorities and households containing single parent families, stepfamilies, recently married couples, and cohabiting couples. A total of 2390 AfricanAmerican respondents were included in the study. The 1992-93 survey includes an interview of all surviving members of the original sample. A total of 10008 respondents were reinterviewed; this represents an attrition rate of 23 per cent.

We limited our analysis to those respondents who were between 17 and 65 years of age in 1987, and who were reinterviewed in 1992-93. The total number of respondents included in our analysis was 8029; of those 1369 were African-American and 6660 white people. We used two strategies to better control for a possible reverse causation effect. Firstly, we only included those that in 1987 reported not having any physical or mental limitation that would prevent them from working; and secondly, we controlled for previous depression and employment history.

MEASURES

We used two outcome measures. The first measure was a depression index created from the responses to 15 items of the Center for Epidemiological Studies' Depression Scale (CES-D) included in the survey; the reliability and validity of these items has been reported elsewhere. ${ }^{34}$ The possible response range was 0 to 105 . The second measure was a self reported measure of perception of overall health status. The outcome measure of how respondents would describe their health compared with other people their age consisted on a 5 point scale (1-very poor; 5-excellent), and we reduced it to two groups. Good or excellent health; compared with fair, poor, or very poor health.

An employment variable was constructed from several variables that asked about respondents' employment and sources of income in 1992. Employed respondents were categorised into full and part time employed, depending on whether they worked 30 hours or more, or 29 or less a week.

When comparing unemployed people to those employed, one of the most obvious critiques is that, if we included all employed into a single category, we would be putting together those who have favourable working conditions with those that may have unfavourable and even health threatening jobs, (E Rodriguez, et al, International congress on women, work and health, Barcelona, 1996) thus, making their comparison with unemployed people less meaningful. Therefore, we divided the employed population (both full and part time workers) into two categories according to their self reporting of whether or not they were satisfied with their jobs. Satisfaction with paid job was rated on a 7 point scale. We put together those who were satisfied or very satisfied, and the rest were classified as "others", or less than satisfied with their current employment situation. We should note that we do not have a clear understanding of the causes that are related to satisfaction with employment. Those could range from satisfaction with coworkers and supervisors, to schedule preferences or benefits packages. Nevertheless, we consider that overall satisfaction with employment should be taken into consideration. In addition, we created a different category of those working people who were simultaneously receiving welfare benefits, and followed the same strategy of dividing them into satisfied and less than satisfied with their employment. Given the low number of men working and receiving welfare, we only included these groups in the analysis of the female population.

Respondents who were not working for pay or were completely retired were grouped into different categories of unemployment. We defined unemployed as any person not holding a job, regardless of whether they were actively looking for work or not. Firstly, those looking for work during the four weeks before the interview, and those not actively looking for work were separated into two categories. Then, each of those groups were further divided into three categories: (a) people receiving public assistance, including AFDC, general assistance, food stamps or energy assistance; (b) people who were receiving income from entitlement government benefit programmes, such as veterans' benefits, unemployment compensation, worker's compensation or supplemental security income; (c) people who were not receiving any type of income or economic assistance. This last group of nonworking people is difficult to interpret; we do not know how many of those are housewives by choice, students, or simply discouraged unemployed persons not eligible for any kind of 
Table 1 Depression index (0-105). Means and standard deviation of depression index for different employment status groups

\begin{tabular}{|c|c|c|c|c|}
\hline & \multicolumn{2}{|l|}{ Women } & \multicolumn{2}{|l|}{ Men } \\
\hline & $\begin{array}{l}\text { African-American mean } \\
(S D) / \text { number }\end{array}$ & White mean (SD) / number & $\begin{array}{l}\text { African-American mean } \\
(S D) / \text { number }\end{array}$ & White mean (SD) / number \\
\hline \multicolumn{5}{|l|}{ Employment status 1992} \\
\hline Full time work/satisfied with jobs & $18.49(20.37) / 291$ & $14.49(15.35) / 1220$ & $13.46(16.92) / 213$ & $11.08(11.97) / 1358$ \\
\hline Full time work/others & $24.52(22.16) / 146$ & $21.81(17.76) / 466$ & $18.81(18.53) / 90$ & $16.98(15.87) / 524$ \\
\hline Part time work/satisfied with jobs & $14.20(15.96) / 30$ & $13.18(14.52) / 354$ & $18.25(24.03) / 16$ & $8.30(9.63) / 69$ \\
\hline Part time work/others & $24.52(23.18) / 25$ & $24.09(23.80) / 127$ & $\mathrm{~N} / \mathrm{A}$ & $13.59(14.29) / 41$ \\
\hline Working W/welfare/satisfied with jobs & $29.73(25.53) / 22$ & $21.08(24.30) / 24$ & N/A & N/A \\
\hline Working W/welfare/others & N/A & N/A & N/A & N/A \\
\hline Unemp/looking for work & $28.25(24.49) / 16$ & $25.33(24.11) / 45$ & N/A & $17.81(19.77) / 47$ \\
\hline Unemp/not looking W/benefits & $33.85(26.62) / 62$ & $31.30(24.44) / 104$ & N/A & $21.71(18.89) / 34$ \\
\hline Unemp/not looking W/no benefits & $26.90(25.82) / 147$ & $18.63(20.41) / 730$ & $18.25(20.02) / 52$ & $20.69(24.56) / 138$ \\
\hline Completely retired & $15.96(19.03) / 53$ & $16.02(19.01) / 263$ & $11.40(15.06) / 25$ & $11.92(15.70) / 146$ \\
\hline
\end{tabular}

benefits. No question included in the survey allowed us to differentiate among those three groups of people included in the same category of non-employed and not looking for work without receiving any benefits.

Those who were completely retired in 1992 were in a separate category. Tables 1 and 2 show levels of depression and general health perception for the different employment groups. The type of employment situations was operationalised as dummy variables, with the satisfied full time employed category as the comparison group in the equation of our multiple regression models described in the results section of our paper.

In addition, the following factors were included in our analysis:

1 individual characteristics: age, and whether or not the respondent reported any physical or mental condition that would limit their ability to work for pay in 1992;

2 education: years of education in 1992, and whether or not the respondent attended any type of training or schooling between 1987 and 1992;

3 household characteristics: Being a household head. Total household income (controlling for number of household members), total family assets, and total debts;

4 informal social support: marital status, frequency of social contacts, and satisfaction with relationships (family and friends);

5 job search history: weeks unemployed in 1991 (that is, year before the second interview was conducted);

6 environmental variables: percentage of unemployment in the state, and per capita dollars available for unemployment subsidy in the state of residency;
71987 employment status, index of depression or health status, and social support available.

STATISTICAL ANALYSIS

Multiple regression analyses examined the relation between depression and other factors. Our outcome variable was a scale with a range of 0-105. We transformed the index of depression to $\log$ (depression +0.05 ) to better fit the assumptions of multiple regression analyses. We used a Box-Cox transformation of the income, assets and debts variables, a frequently used procedure to better deal with outlying values. The transformations were sufficient to produce reasonable residual plots. The appropriate regression diagnostic tests were performed to assess the fit of the model.

The analysis was constructed to make the best use of the longitudinal design to examine the impact of unemployment and other factors on depression. The outcome variable was depression in 1992. Depression in 1987 was included as a covariate. As earlier depression was controlled, the regression coefficients for unemployment and the other factors included in regression models estimated the effects of these variables on changes in depression that occurred between 1987 and 1992. We used a dynamic model, appropriate for the analysis of longitudinal data, which incorporates the time elapsed between data collection points by modeling events in discrete time. ${ }^{35}$

The classic assumptions of correct specification, homoscedasticity, and normality were checked by analysing the residual plots. In addition, diagnostic tests were performed for collinearity and no problems were found. Only two variables, assets and debts, had a relatively

Table 2 General health perception (1-5). Means and standard deviations of general health perception for different employment status groups

\begin{tabular}{|c|c|c|c|c|}
\hline & \multicolumn{2}{|l|}{ Women } & \multicolumn{2}{|l|}{ Men } \\
\hline & $\begin{array}{l}\text { African-American mean } \\
(S D) / \text { number }\end{array}$ & White mean (SD) / number & $\begin{array}{l}\text { African-American mean } \\
(S D) / \text { number }\end{array}$ & White mean (SD) / number \\
\hline \multicolumn{5}{|l|}{ Employment status 1992} \\
\hline Full time work/satisfied with jobs & $4.10(0.71) / 313$ & $4.18(0.68) / 1247$ & $4.20(0.69) / 222$ & $4.15(11.97) / 1382$ \\
\hline Full time work/others & $3.90(0.75) / 153$ & $3.85(0.76) / 469$ & $4.06(0.70) / 93$ & $3.93(0.75) / 537$ \\
\hline Part time work/satisfied with jobs & $4.06(0.89) / 34$ & $4.07(0.71) / 362$ & $4.0(0.87) / 17$ & $3.93(0.88) / 71$ \\
\hline Part time work/others & $3.59(0.97) / 27$ & $3.93(0.84) / 132$ & N/A & $4.14(0.65) / 42$ \\
\hline Working W/welfare/satisfied with jobs & $4.00(0.76) / 25$ & $4.00(0.69) / 26$ & N/A & N/A \\
\hline Working W/welfare/others & N/A & N/A & N/A & N/A \\
\hline Unemp/looking for work & $3.76(0.90) / 17$ & $3.82(0.86) / 49$ & $\mathrm{~N} / \mathrm{A}$ & $3.88(0.68) / 51$ \\
\hline Unemp/not looking $\mathrm{W} /$ benefits & $3.52(1.04) / 71$ & $3.49(1.11) / 107$ & N/A & $3.49(1.07) / 35$ \\
\hline Unemp/not looking W/no benefits & $3.84(0.87) / 167$ & $3.93(0.88) / 764$ & $3.75(1.03) / 56$ & $3.65(1.04) / 142$ \\
\hline Completely retired & $3.45(0.92) / 58$ & $3.88(0.87) / 289$ & $3.59(1.12) / 29$ & $3.73(0.91) / 150$ \\
\hline
\end{tabular}

N/A These groups were to small to attribute statistical significance. 
high correlation (close to 0.50 ), but this was not problematic because subsequent collinearity analysis using condition indices confirmed the appropriateness of including both variables in the model.

We used a logistic regression model to analyse the prediction of perceived health status. We did not replace any missing values in the dependent variables. For the categorical independent variables we added an option of "no response" where necessary, in order to include all respondents in our analysis. For the continuous independent variables (income, assets and debts), we replaced missing values by imputing them with the predicted value for the age, sex, ethnic, marital, and occupational group of the respondent.

\section{Results}

DESCRIPTIVE ANALYSIS

Index of depression

Both African-American and white women had more symptoms of depression than their male counterparts (see table 1). Among both African-American and white women, those employed part time and who reported satisfaction with their jobs reported lower indices of depression. Among African-American people, the retired and full time employed satisfied with their jobs were next in reporting low depression; the same groups reported lower depression among white people but in reverse order.

Among African-American people, the most depressed were the unemployed women looking for work while receiving welfare or other government benefits, followed by those who were receiving welfare and were either not working and not looking for work, or employed but not satisfied with their jobs. In reporting symptoms of depression, no difference was found between welfare recipients not working or working but not satisfied with their jobs ${ }^{\star}$; only those who were receiving welfare and satisfied with their jobs reported slightly lower depression. Among white people, the most depressed were those receiving welfare while unemployed, followed by those receiving welfare and working simultaneously but not satisfied with their jobs.

In most employment groups, AfricanAmerican people reported higher indices of depression, with the exception of non-working welfare recipients. Among this group, white people reported slightly higher depression than black people. An interesting difference is that the non-working white population (not actively looking for work and not receiving any type of benefits) reported lower depression than working women (both full and part time employed) not satisfied with their jobs; among AfricanAmerican people, the same group of nonworking women (not actively looking for work and not receiving any type of benefits) reported higher depression than the dissatisfied employed.

*The number of repondents working while receiving welfare and not satisfied with their jobs was very small and given that it is not possible to attribute statistical significance, we do not show them in our tables.
KEY POINTS

- Employment situation was related to depression for white men and women, but not consistently for African-American.

- Household income was not significantly related to depression after controlling for assets and debts.

- Wealth indicated by total assets was a predictor of depression for white but not for African-American people.

- For all four groups, satisfaction with personal relationships (including family and friends) was positively associated with better health status.

General health perceptions

Regarding general health perceptions, we observe a similar pattern (see table 2). For both African-American and white populations, those who report better health status are the full and part time employed satisfied with their jobs, followed by the welfare recipients who work and are satisfied with their jobs. The groups that report lower health levels are unemployed women, especially those not actively looking for work and receiving welfare benefits.

MULTIPLE REGRESSION AND LOGISTIC

REGRESSION ANALYSIS

Index of depression

Table 3 presents the results of our multiple regression model including the variables that we hypothesised could have an impact on depression in 1992, while controlling for occupational status and other variables in 1987. The significant factors for depression observed for all groups include: having a physical or mental condition that would limit the ability of working for pay; not being satisfied with their relationships with family and friends; and the index of depression previously reported in 1987. Age was significant in all groups except white men. In addition, years of education was related to lower depression symptoms for all groups, with the exception of AfricanAmerican women.

Some of the most notable differences between black and white women include the impact of years of education. While for white women, more years of education was related to lower symptoms of depression, years of education was not significant in reducing depression among African-American women. The same difference is observed regarding the impact of attending school between the interview periods (1987-1992). While being divorced, widowed or separated was significantly related to depression among white women, there were no significant differences for African-American women. In contrast, being the head of the household was associated with more symptoms of depression among African-American women but not among white women.

We observed other differences between African-American and white men. Longer periods of unemployment in 1991 was related to a lower depression index for white men, 
Table 3 Depression index (1992). Parameter estimates and standard errors from regression model

\begin{tabular}{|c|c|c|c|c|}
\hline & \multicolumn{2}{|l|}{ Women } & \multicolumn{2}{|l|}{ Men } \\
\hline & $\begin{array}{l}\text { African-American } \\
\text { estimate (SE) }\end{array}$ & $\begin{array}{l}\text { White } \\
\text { estimate (SE) }\end{array}$ & $\begin{array}{l}\text { African-American } \\
\text { estimate (SE) }\end{array}$ & $\begin{array}{l}\text { White } \\
\text { estimate (SE) }\end{array}$ \\
\hline \multicolumn{5}{|l|}{ Employment status in 1992} \\
\hline \multicolumn{5}{|l|}{ Full time work/satisfied with job (referent) } \\
\hline Full time work/others & $0.079(0.131)$ & $0.269^{\star \star \star}(0.058)$ & $0.150(0.178)$ & $0.198^{\star \star \star}(0.060)$ \\
\hline Part time work/satisfied with job & $-0.298(0.231)$ & $-0.059(0.063)$ & $0.297(0.354)$ & $0.158(0.140)$ \\
\hline Part time work/others & $0.049(0.267)$ & $0.237^{\star \star}(0.094)$ & N/A & $0.110(0.175)$ \\
\hline Working W/welfare/satisfied with job & $0.436(0.317)$ & $-0.283(0.296)$ & N/A & N/A \\
\hline Unemp/looking for work & $0.369(0.374)$ & $-0.043(0.175)$ & N/A & $0.312^{\star}(0.169)$ \\
\hline Unemp/not looking W/benefits & $0.151(0.196)$ & $0.418^{\star \star \star}(0.117)$ & N/A & $0.252(0.224)$ \\
\hline Unemp/not looking W/no benefits & $-0.151(0.148)$ & $0.063(0.054)$ & $0.035(0.245)$ & $0.024(0.105)$ \\
\hline Completely retired & $0.116(0.227)$ & $0.098(0.081)$ & $0.123(0.342)$ & $-0.012(0.116)$ \\
\hline \multicolumn{5}{|l|}{ Any physical or mental condition in 1992} \\
\hline Limiting a lot work for pay & $0.739^{\star \star \star}(0.155)$ & $0.612^{\star \star \star}(0.085)$ & $0.862^{\star \star \star}(0.272)$ & $0.552^{\star \star \star}(0.130)$ \\
\hline Years of education in 1992 & $-0.012(0.022)$ & $-0.018^{\star \star}(0.008)$ & $-0.056^{\star \star}(0.025)$ & $-0.030^{\star \star \star}(0.009)$ \\
\hline \multicolumn{5}{|l|}{ Marital status in 1992} \\
\hline Divorced, widow/er or separated & $-0.040(0.122)$ & $0.162^{\star \star \star}(0.052)$ & $0.419^{\star \star}(0.187)$ & $0.060(0.083)$ \\
\hline Never married & $0.033(0.138)$ & $-0.048(0.076)$ & $0.411^{\star}(0.238)$ & $0.126(0.088)$ \\
\hline \multicolumn{5}{|l|}{ Household characteristic in 1992} \\
\hline †Income in thousands of dollars & $-0.077(0.106)$ & $-0.041(0.043)$ & $-0.103(0.156)$ & $-0.024(0.058)$ \\
\hline tAssets in thousands of dollars & $-0.090(0.068)$ & $-0.087^{\star \star}(0.033)$ & $0.065(0.112)$ & $-0.110^{\star \star \star}(0.042)$ \\
\hline †Debts in thousands of dollars & $0.163(0.104)$ & $-0.105^{\star \star \star}(0.040)$ & $0.138(0.142)$ & $0.056(0.050)$ \\
\hline \multicolumn{5}{|l|}{ Social support in 1992} \\
\hline Satisfied with relationships (family, friends, etc) & $-0.145^{\star \star \star}(0.019)$ & $-0.150^{\star \star \star}(0.008)$ & $-0.151^{\star \star \star}(0.30)$ & $-0.133^{\star \star \star}(0.010)$ \\
\hline \multicolumn{5}{|l|}{ Job search history } \\
\hline ‡Weeks unemployed in 1991 & $-0.005(0.006)$ & $-0.003(0.00)$ & $-0.004(0.009)$ & $-0.013^{\star \star \star}(0.004)$ \\
\hline \multicolumn{5}{|l|}{ Environmental factors } \\
\hline \multicolumn{5}{|l|}{ State unemployment compensation in millions paid in } \\
\hline 1992 (per 1000 unemployed) & $0.008(0.028)$ & $0.023^{\star \star}(0.012)$ & $-0.001(0.043)$ & $-0.004(0.015)$ \\
\hline Index of depression in 1987 & $0.265^{\star \star \star}(0.034)$ & $0.345^{\star \star \star}(0.014)$ & $0.225^{\star \star \star}(0.045)$ & $0.266^{\star \star \star}(0.018)$ \\
\hline Intercept & $3.461^{\star \star \star}(0.635)$ & $3.557^{\star \star \star}(0.242)$ & $3.784^{\star \star \star}(0.849)$ & $3.889^{\star \star \star}(0.294)$ \\
\hline Standard error & 0.916 & 0.990 & 1.093 & 1.225 \\
\hline$r^{2}$ & 0.269 & 0.325 & 0.298 & 0.250 \\
\hline DF (model) & 34 & 34 & 31 & 31 \\
\hline $\mathrm{DF}$ (error) & 766 & 3304 & 387 & 2318 \\
\hline Prob $>F$ & 0.0001 & 0.0001 & 0.0001 & 0.0001 \\
\hline
\end{tabular}

$\overline{\star \star \star} \mathrm{p}<0.01,{ }^{\star \star} \mathrm{p}<0.05,{ }^{\star} \mathrm{p}<0.10$. Positive value of a parameter estimate indicates a high value of Index of Depression in 1992, whereas a negative value indicates a low value of Index of Depression in 1992. The model controls for age, being a household head in 1997, employment status in 1987, and 1987 measures of social support: frequency of social contacts, and having someone to call in an emergency, state unemployment rate in 1992, frequency of social contacts in 1992, number of household members, and whether the respondent attended school between 1987 and 1992. †Transformed variables: log (Index of Depression 1992 + 0.05). Log (Index of Depression $1987+0.05)$, (income in thousands of dollars) $)^{0.25}$, (assets in thousands of dollars) $)^{0.2}$, (debts in thousands of dollars) ${ }^{0.1}$.

while no significant impact was observed among African-American men. In contrast with what we see among women, divorced, widower or separated black men were more likely to be depressed than married ones, but no significant difference was observed among white men.

Household income was not significantly related to depression after controlling for assets and debts. Total assets were significant for white people but not for African-Americans. Debts were only significant for white women.

While wealth indicated by total assets is a significant predictor of depression for white people even after controlling for all the other variables included in the model, it is not the case for African-American people. Being a household head was related to more symptoms of depression among African-American, but not among white people.

For African-American women, there was no statistical difference among employment groups. After controlling for all the factors included in our model, the employment situation did not influence the likelihood of reporting depression for African-American women. The higher index of depression observed among the unemployed in relation to those satisfactorily employed (see table 1) was not significant when other personal and socioeconomic factors are controlled for in the analysis.

In contrast for white women, there was a significantly higher index of depression among those employed but not satisfied with their jobs. White women also reported more depression symptoms while being unemployed and receiving social benefits (mostly welfare).

White and African-American men were significantly more depressed when unemployed and looking for work, but being unemployed for a longer period during the previous year had a protective effect on depression for white men.

\section{Health status}

For all four groups, satisfaction with personal relationships (including family and friends) was positively associated with better health status, and having a physical or mental condition that would limit the ability to work for pay was inversely related to health perception as was the case with previous reports of poor health in 1987 (see table 4).

Several factors were significant for white people but not for African-American people in predicting health status: years of education, total household assets, and the amount of unemployment benefits available at the state level.

Age was associated with reporting worse health status among both groups of men, but it was not significant for women. Interestingly, white men who were divorced, widowed or separated reported better health status than married men.

When comparing people with different employment statuses in 1992, employment status among African-American men was not a 
Table 4 Health status. Odds ratios and 95\% confidence intervals from logistic regression model: response variable: health compared with people your age is good or excellent versus fair, poor or very poor ( $0=$ fair, poor or very poor health, $1=$ excellent or good health) *

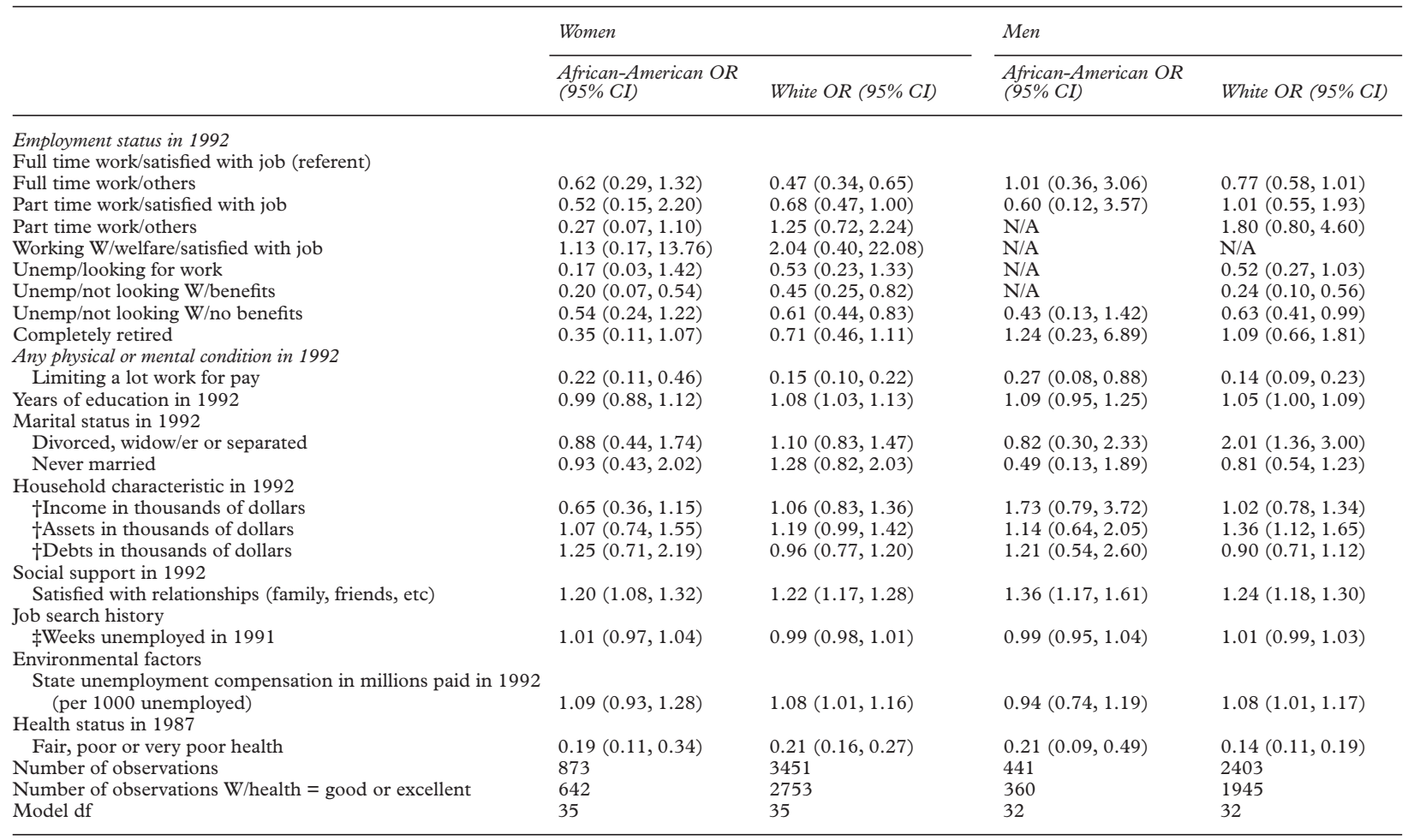

* Odds ratios greater than 1 indicate good health status in 1992, whereas odds ratios less than 1 indicate poor health status. The model controls for age, being a household head in 1997, employment status in 1987, and 1987 measures of social support: frequency of social contacts, and having someone to call in an emergency, state unemployment rate in 1992, frequency of social contacts, number of household members, and whetehr the respondent attended school between 1987 and 1992. †Transformed variables: long (Index of Depression $1987+0.05)$, (income in thousands of dollars) $)^{0.25}$, (assets in thousands of dollars) ${ }^{0.2}$, (debts in thousands of dollars) $)^{0.1}$.

significant variable in predicting health status. Among African-American women only being unemployed while receiving benefits was significantly related to a higher likelihood of reporting fair or poor health status. Among white men, and women, unemployed people not looking for work reported significantly worse health status when compared with the fully employed. Among the employed white women, those who were not satisfied with their jobs also reported worse health.

\section{Discussion}

This study relies on self reported survey data, and its strengths and limitations depend ultimately on factors related to the correct assessment of theoretical and statistical assumptions of the analytical model, the adequate - albeit never perfect - way of dealing with missing values and attrition, and the causal inferences made in interpreting the results. ${ }^{36}$

We are confident that our study can facilitate a better understanding of what aspects of the individual and social environment contribute to reducing the negative influence of stressors such as unemployment. However, interpretations of causality should be made cautiously. For instance, people receiving benefits differ in many ways from people not receiving benefits, and these may not be fully controlled through the background covariates used in our analysis. Our exclusion criteria, and the factors we control for in our model, should eliminate most of the differences among the various groups of unemployed people, but uncontrolled variables determining both unemployment resources and health outcomes may still exist. One of the strengths of the study was the use of longitudinal data to specify the direction of the relation.

No significant differences in levels of health status were found between employed and unemployed African-American men, nor in depression for African-American women. In addition, white men and women not satisfied with their jobs reported higher depression levels than those satisfied with their jobs and unemployed not looking for work report lower health status.

It could be that African-American people do not derive the same satisfaction from employment that white people do. It is true, however, that the historical imprints of slavery, emancipation, Jim Crow Laws`, segregation, the Civil Rights Struggle, discrimination, and institutional racism have affected the degree to which a range of coping strategies have been adopted by African-American people. The unpredictability of continuous employment resulting

*During the early 20th century, racial subordination was re-established as Jim Crow statutes were introduced, creating two societies, one black and one white, separate and unequal. In 1896, a legal precedent was established by the Supreme Court in the Plessy $v$ Ferguson decision that sanctioned a "separate but equal" doctrine, creating a system of apartheid in which Jim Crow laws were passed by legislatures of the Southern states based on the belief than even though slavery had been abolished, black people were inherently inferior and not worthy of the full rights of citizenship granted by the Civil Rights Act of 1875 and the Fourteenth Amendment. 
from periodic economic shifts, structured societal inequality, and societal attitudes about race have made it necessary for this group to depend less upon employment for their general sense of well being and mental health. ${ }^{37}$ In fact, as shown in table 1, African-Americans reported higher incidences of depression in most employment status groups than their white counterparts.

Alternative explanations may suggest firstly that African-American men and women may be employed largely in situations where access to health and mental health benefits are not widely available or secondly, that trust in the medical profession has been so compromised that regular health evaluations (preventive visits to health care providers) are not done.

Among both African-American and white women, no difference was found between those working while receiving welfare and the full time satisfactorily employed. However, it would be precipitous to extrapolate this finding to the new situation created by the recent welfare reform, legislation, in which working will be a compulsory requirement for a larger segment of welfare recipients.

Years of education was a significant predictor of lower depression and better health status among white people, but it was not related to health status among African-American men or women, and significantly related to depression only among men. Once more, it could be that factors not included in our model (for example, racial discrimination) are a reality in the lives of African-Americans, so that the gains obtained by education are not as directly observable as among white people. The same could be said about the lack of significant impact of household assets for African-Americans, while for white people more wealth significantly predicts lower depression and better health status. In all models income was not significant when wealth and assets are controlled for in this study, which suggests that total family assets may be a better measure of social class than household income.

In conclusion, our study challenges some of the conventional knowledge when applied to African-American people. While education has a clear impact on depression and well being among white people, why is it that the association is less significant for AfricanAmericans, and especially for AfricanAmerican women? While reporting satisfaction with employment is significantly associated with better mental health (in comparison with those not satisfied with their work) among white people, why is it that we do not see a significant difference among African-American people when we control for the other factor in our model? And why are greater assets associated with better mental health and well being among white people but not among African-American people?

In this paper we speculate about possible answers to these questions, but more important than our own speculations and interpretations are the questions themselves. They open the way to a-if not new-very necessary line of inquiry to better understand the dynamics of health and illness among the different groups in the population. By continuing to study these issues and pursuing the questions we will be able to better understand the increasing health and mortality differences between AfricanAmerican and white people observed in the same occupational categories. ${ }^{39}$ Only then can we encourage the best ways of fostering the well being of all segments of the population.

We would like to thank Cornell Agricultural Experiment Station for the award of a Hatch Grant that made possible this research effort. The data were generously provided by the Centre for Demography and Ecology at the University of WisconsinDemography and Ecology at the University of Wisconsin-
Madison. The National Survey of Families and Households Madison. The National Survey of Families and Households (NSFH) was funded by a grant (HD21009) from the Centre for
Population Research of the National Institute of Child Health Population Research of the National Institute of Child Health out at the Centre for Demography and Ecology at the University of Wisconsin-Madison under the direction of Larry Bumpass and James Sweet. Field work was done by the Institute for Survey Research at Temple University. We specially thank Dr Stanislav Kasl, and three anonymous readers for comments on a previous version of the paper.

1 US Department of Labor. Employment and earnings. Bureau of Labor Statistics, April. Washington, DC: US Government Printing Office, 1997

2 Wozniak R. Black workers still need good jobs, higher pay. AFLCIO Economic Research Department, Report No78. 1994.

3 Avery RB, Rendall MS. The contribution of inheritances to black-white and Hispanic-white disparities in the United States. Ithaca: Cornell University, Labor Economics Workshop, 1997.

4 Duncan GJ. Income dynamics and health. Int f Health Serv 1996;26:419-44.

5 Marmot MG, Bobak M, Smith GD. Explanation for social inequalities in health. In: Amick B, Levine S, Tarlov A, et al, eds. Society and health. New York: Oxford University Press, 1995: $172-210$.

6 Mcisaac SJ, Wilkinson RG. Income distribution and causespecific mortality. Eur f Public Health 1997;7:45-53.

7 Pritchett L, Sumers LH. Wealthier is healthier. Fournal of Human Resources 1996;31:840-68.

8 Wannamethee SG, Shaper AG. Socioeconomic status within social class and mortality: a prospective study in middleaged British men. Int F Epidemiol 1997;26:532-41.

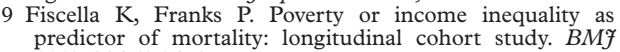
1997;314:1724-8.

10 Stronks K, Van De Mheen H, Van Den Bos J, et al. The interrelationship between income, health and employment status. Int F Epidemiol 1997;26:592-600.

11 Elkeles T, Seifert W. Unemployment and health impairments. Longitudinal analyses for the Federal Republic of Germany. Eur f Public Health 1993;3:28-37.

12 Elkeles T. Arbeitswelt und Risiken fur RuckenschmerzenPotentiale fur arbeitsweltbezogene Pavention un Gesundheitsforderung. Publication series of the research group Health Risks and Preventive policy. Berlin: WissenschaftHealth Risks and Preventive policy. Berlin:
szentrum Berlin fur Sozialforschung, 1994.

13 Riphanhn R. Older workers' response to health shocks. Second Annual GSOEP User's Conference. PotsdamBabelsberg, Germany: GSOEP, 1996

14 Jahoda M, Lazarsfield PF, Zeisl H. Marienthal: the sociography of an unemployed community. London: Tavistock, 1972 15 Bakke EW. The unemployed man. London: Nisbet, 1933.

16 Fagin L, Little M. The forsaken families. London: Penguin Books, 1984.

17 Jahoda M. Employment and unemployment. A socialpsychological analysis. Cambridge: Cambridge University Press, 1982

18 Brenner MH. Economic instability, unemployment rates, behavioral risks, and mortality in Scotland 1952-83. Int $\mathcal{f}$ Health Serv 1987;17:475-87.

19 Catalano R. Health effects of economic insecurity. Am 7 Public Health 1991;81:1148-51.

20 Catalano R, Dooley D, Jackson R. Economic predictors of admissions to mental health facilities in a nonmetropolitan community. F Health Soc Behav 1981;22:28-97

21 Eyer J. Does unemployment cause the death rate peak in each business cycle? A multifactor model of death rate change. Int $\mathcal{F}$ Health Serv 1977;7:625-63.

22 Arber S. Integrating nonemployment into research on health inequalities. Int $\mathcal{F}$ Health Serv 1996;26:445-81.

23 Brenner H. Political economy and health. In: Amick B, Levine S, Tarlov A, et al. Society and health. New York: Oxford University Press, 1995:211-46.

24 Kasl SV, Rodriguez E, Lasch K. The impact of unemployment on health and well-being. Dohrenwend BP, ed. Adversity, stress, and psychopathology. New York: Oxford University Press, 1998:111-31.

25 Shortt SED. Is unemployment pathogenic? A review of current concepts with lessons for policy planners. Int $\mathcal{F}$ Health Serv $1996 ; 26: 569-89$.

26 King S, Williams DR. Race and health a multidimensional approach to African American health. In: Amick B, Levine approach to African American health. In: Amick B, Levine
S, Tarlov A, et al, eds. Society and health. New York: Oxford University Press, 1995:93-130. 
27 Rodriguez E, Lasch K, Mead JP. The potential role of unemployment benefits in shaping the mental health impact of
unemployment. Int f Health Serv 1997;27:601-23.

28 United Nations. World Summit for social development. New York: United Nations, 1995.

29 Kesler RC, Neighbors HW. A new perspective on the relationship among race, social class, and psychological distress. F Health Soc Behav 1986;27:107-15.

30 Williams DR. Race/ethnicity and socioeconomic status: measurement and methodological issues. Int J Health Serv 1996;26:483-505.

31 Muntaner C, Nieto JF, Patricia OC. The bell curve: on race, social class, and epidemiological research. Am 7 Epidemiol 1996;144:531-6.

32 Navarro V. Dangerous to your health. New York: Monthly Review Press, 1993.

33 Guralnik JM, Leveille SG. Annotation: race, ethnicity, and health outcomes - unraveling the mediating role of sociohealth outcomes-unraveling the mediating role of
34 Ross CE, Mirowsky J. Socially-desirable response and acquiescence in a cross-cultural survey of mental health. $\mathcal{F}$ Health Soc Behav 1984;25:189-97.

35 Dwyer JH, Feinleib M, Lippert P, et al. Statistical models for longitudinal studies of health. New York: Oxford University Press, 1992.

36 Rodriguez E, Frongillo EA, Chandra, P. Challenges of longitudinal designs in the evaluation of unemployment and welfare Benefits in the U.S." European Evaluation Society, Stockholm, March 6-8, 1997 .

37 Wilson WJ. When work disappears: the world of the new urban poor. New York: Knopf, 1996.

38 Brown DR, Gary LE. Predictors of depressive symptoms among unemployed black adults. Fournal of Sociology and Social Welfare 1985;12:736-54.

39 Barnett E, Armstrong DL, Casper ML. Social class and premature mortality among men: a method for state-based surveillance. Am f Public Health 1997;87:1521-5. 